\title{
Subclinical seizures identified by postoperative electroencephalographic monitoring are common after neonatal cardiac surgery
}

Maryam Y. Naim, MD, ${ }^{a}$ J. William Gaynor, MD, ${ }^{b}$ Jodi Chen, MD, ${ }^{a}$ Susan C. Nicolson, MD, Stephanie Fuller, MD, ${ }^{\mathrm{b}}$ Thomas L. Spray, MD, ${ }^{\mathrm{b}}$ Dennis J. Dlugos, MD, ${ }^{\mathrm{d}}$ Robert R. Clancy, MD, Livia Vianez Costa, MD, ${ }^{\mathrm{d}}$ Daniel J. Licht, MD, ${ }^{\mathrm{d}}$ Rui Xiao, PhD, ${ }^{\mathrm{e}}$ Heather Meldrum, RN, ${ }^{\mathrm{f}}$ and Nicholas S. Abend, MD

\begin{abstract}
Objectives: The American Clinical Neurophysiology Society recommends continuous electroencephalographic monitoring after neonatal cardiac surgery because seizures are common, often subclinical, and associated with worse neurocognitive outcomes. We performed a quality improvement project to monitor for postoperative seizures in neonates with congenital heart disease after surgery with cardiopulmonary bypass.
\end{abstract}

Methods: We implemented routine continuous electroencephalographic monitoring and reviewed the results for an 18-month period. Clinical data were collected by chart review, and continuous electroencephalographic tracings were interpreted using standardized American Clinical Neurophysiology Society terminology. Electrographic seizures were classified as electroencephalogram-only or electroclinical seizures. Multiple logistic regression was used to assess associations between seizures and potential clinical and electroencephalogram predictors.

Results: A total of 161 of 172 eligible neonates (94\%) underwent continuous electroencephalographic monitoring. Electrographic seizures occurred in 13 neonates $(8 \%)$ beginning at a median of 20 hours after return to the intensive care unit after surgery. Neonates with all types of congenital heart disease had seizures. Seizures were electroencephalogram only in 11 neonates $(85 \%)$. Status epilepticus occurred in 8 neonates $(62 \%)$. In separate multivariate models, delayed sternal closure or longer deep hypothermic circulatory arrest duration was associated with an increased risk for seizures. Mortality was higher among neonates with than without seizures $(38 \%$ vs $3 \%, P<.001)$.

Conclusions: Continuous electroencephalographic monitoring identified seizures in $8 \%$ of neonates after cardiac surgery with cardiopulmonary bypass. The majority of seizures had no clinical correlate and would not have been otherwise identified. Seizure occurrence is a marker of greater illness severity and increased mortality. Further study is needed to determine whether seizure identification and management lead to improved outcomes. (J Thorac Cardiovasc Surg 2015;150:169-80)

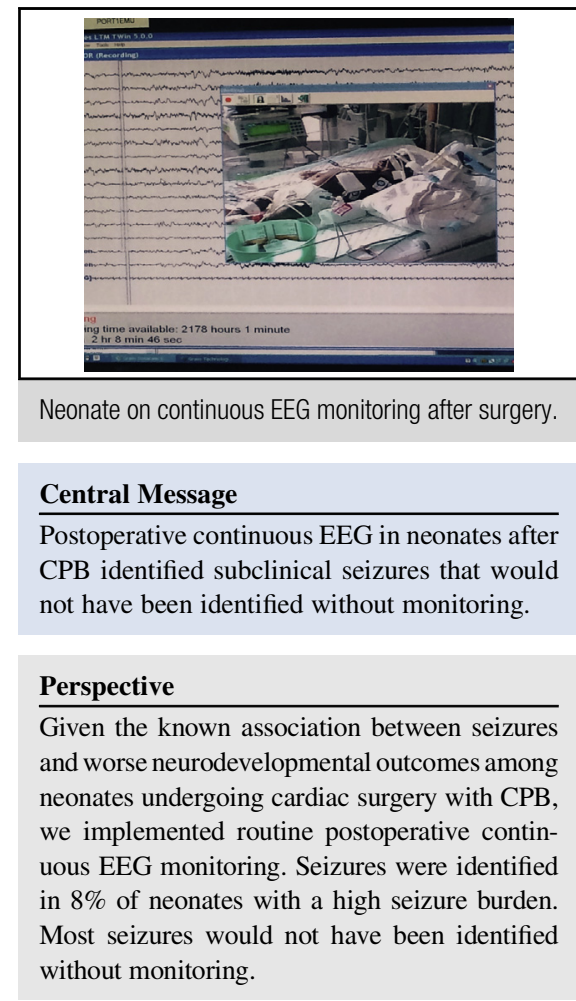

See Editorial page 6.

\footnotetext{
From the ${ }^{a}$ Division of Cardiac Critical Care Medicine, Department of Anesthesiology, Critical Care Medicine, and Pediatrics, ${ }^{\mathrm{b}}$ Division of Cardiothoracic Surgery, Department of Surgery, ${ }^{\mathrm{c}}$ Division of Cardiothoracic Anesthesiology, Department of Anesthesiology and Critical Care Medicine, ${ }^{\mathrm{d}}$ Division of Neurology, Departments of Neurology and Pediatrics, ${ }^{\mathrm{e}}$ Department of Biostatistics and Epidemiology, and ${ }^{\mathrm{f}}$ Department of Nursing, The Children's Hospital of Philadelphia, Perelman School of Medicine at the University of Pennsylvania, Philadelphia, Pa. DJL is funded by National Institutes of Health RO1 NS-072338 and the June and Steve Wolfson Family Foundation. NSA is funded by National Institutes of Health K23NS076550
}

Read at the 94th Annual Meeting of The American Association for Thoracic Surgery, Toronto, Ontario, Canada, April 26-30, 2014.

Received for publication April 25, 2014; revisions received March 9, 2015; accepted for publication March 25, 2015; available ahead of print May 7, 2015

Address for reprints: Maryam Y. Naim, MD, Department of Anesthesiology and Critical Care Medicine, The Children's Hospital Of Philadelphia and Perelman Schoo of Medicine at the University of Pennsylvania, 34th and Civic Center Blvd, Philadelphia, PA 19104 (E-mail: naim@email.chop.edu).

$0022-5223 / \$ 36.00$

Copyright (c) 2015 by The American Association for Thoracic Surgery

http://dx.doi.org/10.1016/j.jtcvs.2015.03.045 


$$
\begin{aligned}
& \text { Abbreviations and Acronyms } \\
& \text { ACNS }=\text { American Clinical Neurophysiology } \\
& \text { Society } \\
& \text { CEEG }=\text { continuous electroencephalographic } \\
& \mathrm{CHD}=\text { congenital heart disease } \\
& \mathrm{CI}=\text { confidence interval } \\
& \mathrm{CICU}=\text { cardiac intensive care unit } \\
& \mathrm{CPB}=\text { cardiopulmonary bypass } \\
& \mathrm{DHCA}=\text { deep hypothermic circulatory arrest } \\
& \mathrm{ECMO}=\text { extracorporeal membrane oxygenation } \\
& \mathrm{EEG}=\text { electroencephalogram } \\
& \mathrm{IQR}=\text { interquartile range } \\
& \mathrm{MRI}=\text { magnetic resonance imaging } \\
& \mathrm{OR}=\text { odds ratio }
\end{aligned}
$$

was used at the discretion of the surgeon after induction of hypothermia to $18^{\circ} \mathrm{C}$. Modified ultrafiltration was performed on all patients. Delayed sternal closure was not routinely used.

\section{Electroencephalogram Monitoring}

CEEG was performed by the encephalography service and initiated within 6 hours of returning to the cardiac intensive care unit (CICU) after surgery. The encephalography service includes acquisition and review software, network infrastructure, licensed EEG technologists, and expert encephalographers. CEEG was performed using a Grass-Telefactor video-EEG system (Grass Technologies, West Warwick, RI) with a portable acquisition machine networked to the main EEG server, allowing EEG review at the bedside, from multiple sites in the hospital, and remotely. EEG technologists were present in the hospital 24 hours per day and 7 days per week. CEEG was performed with 12 gold-over-silver scalp electrodes affixed according to the international 10-20 system (modified for neonates), with collodion adhesive (or paste for neonates on extracorporeal membrane oxygenation [ECMO]). Abnormal movements or vital sign fluctuations noted by the clinical team were marked on the recording as push-button events. If an electrographic seizure was identified, the CICU team was alerted by the EEG technologist or encephalographer, and neurologic consultation was obtained. CEEG was continued for 48 hours if no seizures occurred. If seizures were identified, CEEG was continued until 24 hours after the end of the last seizure. The initial antiseizure medications administered were phenobarbital or levetiracetam at the discretion of the on-call neurologist and cardiac intensivist. Phenobarbital ( $20 \mathrm{mg} / \mathrm{kg}$ bolus) was administered as a first-line agent in the majority of patients. For patients in whom there were concerns for hemodynamic instability, clinicians sometimes used phenobarbital in divided doses $(5 \mathrm{mg} / \mathrm{kg} \times 4$ doses over 1 hour $)$ or levetiracetam ( $20 \mathrm{mg} / \mathrm{kg}$ bolus). Patients with seizures usually underwent clinically indicated magnetic resonance imaging (MRI) of the brain or head ultrasound.

\section{Data Collection}

Clinical data were obtained from the medical record, including anesthesia and perfusion records. Patients were categorized according to a classification that incorporates cardiac anatomy and perioperative physiology, which has been shown to predict perioperative mortality. Class I is 2 ventricles with no aortic arch obstruction, class II is 2 ventricles with aortic arch obstruction, class III is a single ventricle with no aortic arch obstruction, and class IV is a single ventricle with aortic arch obstruction. ${ }^{16}$

For purposes of this review, EEG tracings were reinterpreted by a single encephalographer (NSA), blinded to clinical information (except conceptional age), using standardized ACNS neonatal EEG terminology. ${ }^{17}$ EEG seizures were defined as abnormal, paroxysmal EEG events that were different from the background, lasted more than 10 seconds (or less if associated with a clinical seizure), had a plausible electrographic field, and evolved in frequency, voltage, morphology, and often spatial distribution. EEG seizures were classified as electrographic status epilepticus if any single seizure lasted more than 30 minutes or if recurrent seizures together lasted for more than 30 minutes in any 1-hour epoch (50\% seizure burden). EEG seizures were classified as EEG-only seizures (no clinical signs observed by bedside caregivers or on video review) or electroclinical seizures. All available neuroimaging studies were reviewed by a neurologist (DJL) to examine associations between neuroimaging abnormalities and seizure localization.

Data were collected and managed using Research Electronic Data Capture (REDCap), a web-based electronic data application hosted at the Children's Hospital of Philadelphia Research Institute. ${ }^{18}$

\section{Statistical Analysis}

Summary statistics are reported as medians and interquartile ranges (IQRs) for continuous data and counts and proportions for categoric 
data. The association of each clinical and interictal EEG variable with seizures was examined using the chi-square test for categoric variables and Wilcoxon's rank-sum test for continuous variables.

Multiple logistic regression was used for association of seizures with clinical and interictal EEG variables. To avoid collinearity, correlation between predictors was examined by using Pearson correlation coefficients for continuous predictors, and association between continuous and categoric predictors was examined by 2-sample test or analysis of variance. Variables associated with seizures with a $P$ value less than .2 on univariable analysis were included in multivariable analyses. An initial model used only clinical data, whereas a subsequent model also used data obtained from the initial hour of CEEG. All statistics were performed with Stata 10.0 (StataCorp LP, College Station, Tex).

\section{RESULTS}

\section{Demographics and Surgical Details}

During the 18-month study period, 172 neonates with CHD underwent cardiac surgery with CPB. Postoperative CEEG was obtained in 161 of 172 eligible neonates (94\%). The reasons for not undergoing CEEG included unavailability of EEG machine in 1 neonate, CICU team not ordering CEEG (mainly in the initial phase of implementation) in 5 neonates, death in the operating room in 1 neonate, and CICU team deciding not to monitor in 2 neonates (cutis aplasia in 1 and decision that monitoring was not warranted in 1). Pathway adherence improved over time. For the initial period of monitoring June 15 to December 31, 2012, 48 of 55 neonates $(87 \%)$ who underwent surgery with CPB were monitored. For the middle period from January 1 to June 30, 2013, 54 of 56 neonates $(96 \%)$ were monitored. For the later period of monitoring from July 1 to December 31, 2013, 57 of 59 neonates $(97 \%)$ were monitored.

Of the 161 neonates who underwent CEEG, 92 (57\%) were male. The median gestational age was 39 weeks (IQR, 38-39), and 26 neonates (16\%) were premature $(<37$ weeks gestational age). The median head circumference at birth was $34 \mathrm{~cm}$ (IQR, 32-35). Genetic defects were identified in 21 neonates $(13 \%)$. The median age at surgery was 5 days (IQR, 3-7). Five neonates had 2 operations with $\mathrm{CPB}$ during the neonatal period, and 1 neonate had 3 operations with CPB during the neonatal period. Both were monitored after each surgery.

The cardiac defects were class I in 68 neonates $(42 \%)$, class II in 35 neonates $(22 \%)$, class III in 15 neonates $(9 \%)$, and class IV in 43 neonates $(27 \%)$. The 5 most common operations were the stage I Norwood operation in 43 neonates $(27 \%)$, the arterial switch operation in 25 neonates $(16 \%)$, the systemic to pulmonary artery shunt in 17 neonates $(11 \%)$, complete repair of tetralogy of Fallot in 14 neonates $(9 \%)$, and truncus arteriosus repair in 12 neonates $(8 \%)$. The median duration of $\mathrm{CPB}$ was 46 minutes (IQR, 38-62). DHCA was used in 96 neonates $(60 \%)$, with a median duration of 41 minutes (IQR, $32-50)$. Twenty-six neonates $(16 \%)$ had delayed sternal closure. Eleven neonates $(7 \%)$ required ECMO (2 were
TABLE 1. Demographic and clinical characteristics

\begin{tabular}{lc}
\hline Male, $\mathrm{n}(\%)$ & $92(57 \%)$ \\
Birth weight $(\mathrm{kg})$, median (IQR) & $3.2(2.8-3.6)$ \\
Head circumference (cm), median (IQR) & $34(32-35)$ \\
Gestational age (wk), median (IQR) & $39(38,39)$ \\
Premature neonates (<37 wk gestational age), n (\%) & $26(16 \%)$ \\
Identified genetic defects, n (\%) & $21(13 \%)$ \\
Age at surgery (d) median (IQR) & $5(3-7)$ \\
Cardiac defect, n (\%) & \\
Class I & $43(27 \%)$ \\
Class II & $15(9 \%)$ \\
Class III & $35(22 \%)$ \\
$\quad$ Class IV & $68(42 \%)$ \\
Duration of CPB (min), median (IQR) & $46(38-62)$ \\
DHCA used, n (\%) & $96(60 \%)$ \\
DHCA duration (min), median (IQR) & $41(32-50)$ \\
Delayed sternal closure, n (\%) & $26(16 \%)$ \\
ECMO used, $\mathrm{n}(\%)$ & $11(7 \%)$ \\
Cardiac arrest, $\mathrm{n}(\%)$ & $15(9 \%)$ \\
\hline Number $(\%)$ and median (IQR) are reported as appropriate. IQR, Interquartile range; \\
$C P B$, cardiopulmonary bypass; DHCA, deep hypothermic circulatory arrest; ECMO, \\
extracorporeal membrane oxygenation.
\end{tabular}

placed on ECMO in the operating room before initiation of CEEG, 8 were placed on ECMO during CEEG, and 1 was placed on ECMO while CEEG had been temporarily discontinued during a diagnostic cardiac catheterization). Fifteen neonates $(9 \%)$ had a cardiac arrest (2 in the operating room before initiation of CEEG, 1 in the CICU before initiation of CEEG, and 12 in the CICU during CEEG). Table 1 summarizes the demographic and clinical characteristics.

\section{Nonseizure Events}

Bedside clinicians identified events concerning for clinically evident seizures in 32 neonates (push-button events). None of these events had an EEG correlate, and they were deemed nonepileptic. Push-button events included episodes of abnormal body movement in 14 neonates, hypertension in 7 neonates, tachycardia in 6 neonates, abnormal face movement in 6 neonates, desaturation in 5 neonates, slow respiratory rate in 2 neonates, bradycardia in 1 neonate, and hypotension in 1 neonate. Events occurred during the initial 12 hours in 22 neonates, later than 12 hours in 10 neonates, and during both time periods in 2 neonates.

\section{Seizures and Electroencephalogram Characteristics}

EEG seizures occurred in 13 of 161 neonates $(8 \%)$. The proportion with seizures has not changed since our previous report $^{4}(14 \%$ previously vs $8 \%$ currently, $P=.10)$. The median seizure onset was 20 hours (IQR, 15-34) after return to the CICU postoperatively. EEG seizures were EEG only in 11 neonates $(85 \%)$ and electroclinical in 2 neonates $(15 \%)$. Electrographic status epilepticus occurred in 8 
TABLE 2. Seizure description, treatment, and brain imaging

\begin{tabular}{|c|c|c|c|c|c|}
\hline Subject & $\begin{array}{c}\text { Status } \\
\text { epilepticus }\end{array}$ & $\begin{array}{c}\text { Any seizures } \\
\text { with clinical } \\
\text { correlates } \\
\end{array}$ & Seizure description & $\begin{array}{c}\text { Antiseizure } \\
\text { medications } \\
\text { administered } \\
\end{array}$ & Imaging \\
\hline 1 & Yes & Yes & $\begin{array}{l}25 \text { focal } \mathrm{R} \text { central seizures lasting } \\
0.5-3.5 \mathrm{~min}\end{array}$ & PB & $\begin{array}{l}\text { Brain MRI } \\
\text { Bilateral deep and periventricular foci of PVL }\end{array}$ \\
\hline 2 & Yes & No & 29 bi-occipital seizures lasting 2-30 min & $\mathrm{PB}$ & $\begin{array}{l}\text { Brain MRI } \\
\text { Bilateral deep and periventricular foci of } \\
\text { hemorrhagic PVL }\end{array}$ \\
\hline 3 & Yes & No & $\begin{array}{l}>100 \text { bi-central and vertex seizures } \\
\text { lasting } 0.5-3 \mathrm{~min}\end{array}$ & LEV, PB & $\begin{array}{l}\text { Head US } \\
\text { Bilateral IVH, periventricular hemorrhage vs } \\
\text { hemorrhagic infarct }\end{array}$ \\
\hline 4 & No & No & $\begin{array}{l}1 \mathrm{R} \text { central and } 1 \mathrm{~L} \text { occipital seizure } \\
\text { lasting } 1 \mathrm{~min}\end{array}$ & None & $\begin{array}{l}\text { Brain MRI } \\
\text { Small SDH along flax and tentorium, small } \\
\text { intraparenchymal hemorrhage in R cerebellar } \\
\text { hemisphere and R posterior parietal lobe }\end{array}$ \\
\hline 5 & No & No & $5 \mathrm{~L}$ central seizures lasting $0.25-1 \mathrm{~min}$ & $\mathrm{~PB}$ & $\begin{array}{l}\text { Brain MRI } \\
\mathrm{L} \text { post frontal and anterior parietal infarction, } \\
\mathrm{R} \text { frontal lobe infarction }\end{array}$ \\
\hline 6 & Yes & No & $13 \mathrm{R}$ central seizures lasting $1-3 \mathrm{~min}$ & PB, LEV & $\begin{array}{l}\text { Head US } \\
2 \text { large intraparenchymal lesions in L hemisphere } \\
\text { suggestive of ICH }\end{array}$ \\
\hline 7 & No & No & $9 \mathrm{~L}$ occipital 1-seizures lasting $5 \mathrm{~min}$ & PB & $\begin{array}{l}\text { Brain MRI } \\
\text { Cystic PVL central semiovale and corona radiate } \\
\text { bilaterally }\end{array}$ \\
\hline 8 & Yes & No & 5 bi-occipital seizures lasting $2-13 \mathrm{~min}$ & PB & $\begin{array}{l}\text { Brain MRI } \\
\text { PVL L parietal white matter region, L tentorial SDH, } \\
\quad \text { bilateral cerebral microhemorrhages }\end{array}$ \\
\hline 9 & Yes & No & $34 \mathrm{~L}$ occipital seizures lasting $2-4 \mathrm{~min}$ & LEV & $\begin{array}{l}\text { Brain MRI } \\
\text { PVL corpus callosum, periventricular deep white } \\
\text { matter, microhemorrhages R frontal and parietal } \\
\text { deep white matter, R lateral medulla and cerebellar } \\
\text { peduncle, SDH posterior flax and tentorium }\end{array}$ \\
\hline 10 & Yes & No & $\begin{array}{l}>100 \mathrm{R} \text { frontal-central-temporal temporal } \\
\text { seizures lasting } 0.25-1.5 \mathrm{~min}\end{array}$ & PB, LEV & $\begin{array}{l}\text { Brain MRI } \\
\text { Subacute infarctions in the } \mathrm{R} \text { frontal lobe and } \mathrm{L} \\
\text { frontal lobe }\end{array}$ \\
\hline 11 & No & No & $3 \mathrm{~L}$ occipital seizures lasting $1-20 \mathrm{~min}$ & PB, LEV & $\begin{array}{l}\text { Head US } \\
\text { Increased echogenicity bilateral thalami, bilateral SDH }\end{array}$ \\
\hline 12 & Yes & Yes & $\begin{array}{l}\sim 10 \text { seizures per hour for } 3 \mathrm{~d} \text { from } \\
\quad \text { multifocal locations lasting } 0.5-5 \mathrm{~min}\end{array}$ & PB, LEV & $\begin{array}{l}\text { Head US } \\
\text { Large area of increased parenchymal echogenicity in } \\
\text { the L parietal-occipital region, compatible with } \\
\text { hemorrhagic infarction, IVH left greater than right }\end{array}$ \\
\hline 13 & No & No & 8 diffuse seizures lasting $0.1-2 \mathrm{~min}$ & PB & $\begin{array}{l}\text { Head US } \\
\text { Evolving left caudothalamic groove germinal matrix } \\
\text { hemorrhage with intraventricular synechia }\end{array}$ \\
\hline
\end{tabular}

$P B$, Phenobarbital; $M R I$, magnetic resonance imaging; $P V L$, periventricular leukomalacia; $L E V$, levetiracetam; $U S$, ultrasound; $I V H$, intraventricular hemorrhage; $S D H$, subdural hematoma; $R$, right; $I C H$, intracranial hemorrhage.

neonates $(62 \%)$. Seizures were spatially diffuse in 2 neonates $(15 \%)$, lateralized in 2 neonates $(15 \%)$, and focal in 9 neonates $(69 \%)$. Seizure characteristics are provided in Table 2. The encephalographer performing reinterpretation blinded to clinical information (except conceptional age) was consistent with initial clinical interpretation for seizure occurrence in all patients.

Univariable and multivariable analyses using clinical variables for seizure prediction are shown in Table 3. On univariable analysis, seizures were more common in younger neonates, with longer CBP and DHCA times, in patients with single-ventricle defects with arch obstruction, in patients returned to the CICU with delayed sternal closure, in patients with postoperative cardiac arrests, and in patients who were placed on ECMO. Variables that were not known on return to the CICU and occurred later would not be useful in identifying patients at higher risk for seizures and in need of CEEG on postoperative CICU 
TABLE 3. Electrographic seizure predictors

\begin{tabular}{|c|c|c|c|c|c|c|c|}
\hline \multirow[b]{2}{*}{ Variable } & \multicolumn{3}{|c|}{ Univariate analysis } & \multicolumn{2}{|c|}{ Multivariate analysis no. $1 *$} & \multicolumn{2}{|c|}{ Multivariate analysis no. $2 *$} \\
\hline & No seizures & Seizures & $P$ value & OR $(95 \%$ CI $)$ & $P$ value & OR $(95 \%$ CI $)$ & $P$ value \\
\hline Gender & & & .80 & & & & \\
\hline Male & $85(92 \%)$ & $7(8 \%)$ & & & & & \\
\hline Female & $63(91 \%)$ & $6(9 \%)$ & & & & & \\
\hline Gestational age (wk) & $39(38-39)$ & $37(37-39)$ & .42 & & & & \\
\hline Identified genetic abnormality & & & .55 & & & & \\
\hline None & $128(91 \%)$ & $12(9 \%)$ & & & & & \\
\hline Present & $20(95 \%)$ & $1(5 \%)$ & & & & & \\
\hline Age at surgery $(d)$ & $5(3-7)$ & $3(2-5)$ & .05 & $0.91(0.74-1.11)$ & .36 & $0.93(0.77-1.28)$ & .47 \\
\hline Cardiac defect & & & .14 & & & & \\
\hline Class I & $65(96 \%)$ & $3(4 \%)$ & & $0.46(0.10-2.18)$ & .33 & $1.09(0.18-6.67)$ & .93 \\
\hline Class II & $33(94 \%)$ & $2(6 \%)$ & & $0.49(0.08-2.87)$ & .43 & $0.41(0.07-2.43)$ & .33 \\
\hline Class III & $14(93 \%)$ & $1(7 \%)$ & & $0.76(0.07-7.83)$ & .82 & $2.28(0.14-35.06)$ & .56 \\
\hline Class IV & $36(84 \%)$ & $7(16 \%)$ & & - & & - & \\
\hline Operation & & & .42 & & & & \\
\hline Stage 1 Norwood Operation & $37(86 \%)$ & $6(14 \%)$ & & & & & \\
\hline Arterial switch operation & $24(96 \%)$ & $1(4 \%)$ & & & & & \\
\hline Systemic to pulmonary artery shunt & $16(94 \%)$ & $1(6 \%)$ & & & & & \\
\hline Complete repair of tetralogy of Fallot & $14(100 \%)$ & $0(0 \%)$ & & & & & \\
\hline Truncus arteriosus repair & $11(92 \%)$ & $1(8 \%)$ & & & & & \\
\hline Delayed sternal closure & & & .002 & $3.99(1.04-15.29)$ & .04 & * & * \\
\hline No & $128(95 \%)$ & $7(5 \%)$ & & & & & \\
\hline Yes & $20(77 \%)$ & $6(23 \%)$ & & & & & \\
\hline Duration of DHCA (min) & $21(0-42)$ & $47(36-49)$ & .01 & * & * & $1.04(1.00-1.08)$ & .04 \\
\hline Duration of CPB (min) & $45(38-60)$ & $62(42-77)$ & .24 & & & & \\
\hline ECMO* & & & .015 & $\dagger$ & & & \\
\hline No & $140(93 \%)$ & $10(7 \%)$ & & & & & \\
\hline Yes & $9(73 \%)$ & $3(27 \%)$ & & & & & \\
\hline Cardiac arrest* & & & .006 & $\dagger$ & & & \\
\hline No & $137(94 \%)$ & $9(6 \%)$ & & & & & \\
\hline Yes & $11(73 \%)$ & $4(27 \%)$ & & & & & \\
\hline
\end{tabular}

Number (\%) and median (IQR) are reported as appropriate. Boldface indicates statistical significance. OR, Odds ratio; $C I$, confidence interval; $D H C A$, deep hypothermic circulatory arrest; $C P B$, cardiopulmonary bypass; ECMO, extracorporeal membrane oxygenation. *Delayed sternal closure and DHCA duration were highly correlated, so multivariate analysis included only delayed sternal closure (multivariable analysis no. 1) or DHCA duration (multivariable analysis no. 2). $\dagger$ ECMO and cardiac arrest were not included in the multivariable analysis because these variables would not be known at the time of return to the CICU and therefore could not be used to help decide whether EEG monitoring was indicated.

admission. Thus, cardiac arrest and ECMO were not included in the multivariable model.

Delayed sternal closure and DHCA duration were strongly associated $(P<.0001)$. Therefore, to avoid collinearity, separate multivariate analyses were performed for delayed sternal closure and DHCA duration to examine their respective associations with seizure occurrence. Both multivariate models are provided in Table 3. Both had similar performance characteristics. The goodness-of-fit for the multivariable logistic regression models indicated that both had a pseudo- $\mathrm{R}^{2}$ of 0.11 . Receiver operating characteristic curves (Figure 1) and the c-statistics were not significantly different $(P=.8)$. We performed the leave-one-out cross validation to calculate the predictive probability of seizure occurrence for each individual using the multivariate logistic model and again observed similar results between the 2 models. In their respective models, only delayed sternal closure (odds ratio [OR] 3.99; 95\% confidence interval $[\mathrm{CI}], 1.04-15.29 ; P=.04)$ and DHCA duration (OR, 1.04; 95\% CI, 1.00-1.08; $P=.04$ ) were significantly associated with seizures. Because DHCA was analyzed as a continuous variable, the increase in seizure risk is provided per minute of DHCA. We assessed the potential collinearity of variables. Lower weight was not associated with ECMO $(P=.77)$ or DHCA use $(P=.86)$. Younger age at the time of surgery was not associated with ECMO $(P=.41)$ or DHCA use $(P=.23)$. Arch obstruction was not associated with ECMO $(P=.29)$ but, as expected, was associated with DHCA $(P=.0000)$. When DHCA duration was divided into 3 categories, there was a trend toward higher seizure occurrence with longer DHCA duration (no DHCA 3\%; DHCA $<40$ minutes $7 \%$ with OR, 2.48; 95\% CI, 0.40-15.56; DHCA $\geq 40$ minutes $15 \%$ with OR, 5.36; 95\% CI, 1.09-26.42; chi-square $P=.07$ ). When DHCA was dichotomized to less than 40 minutes (including no DHCA) or 40 minutes or more, neonates 

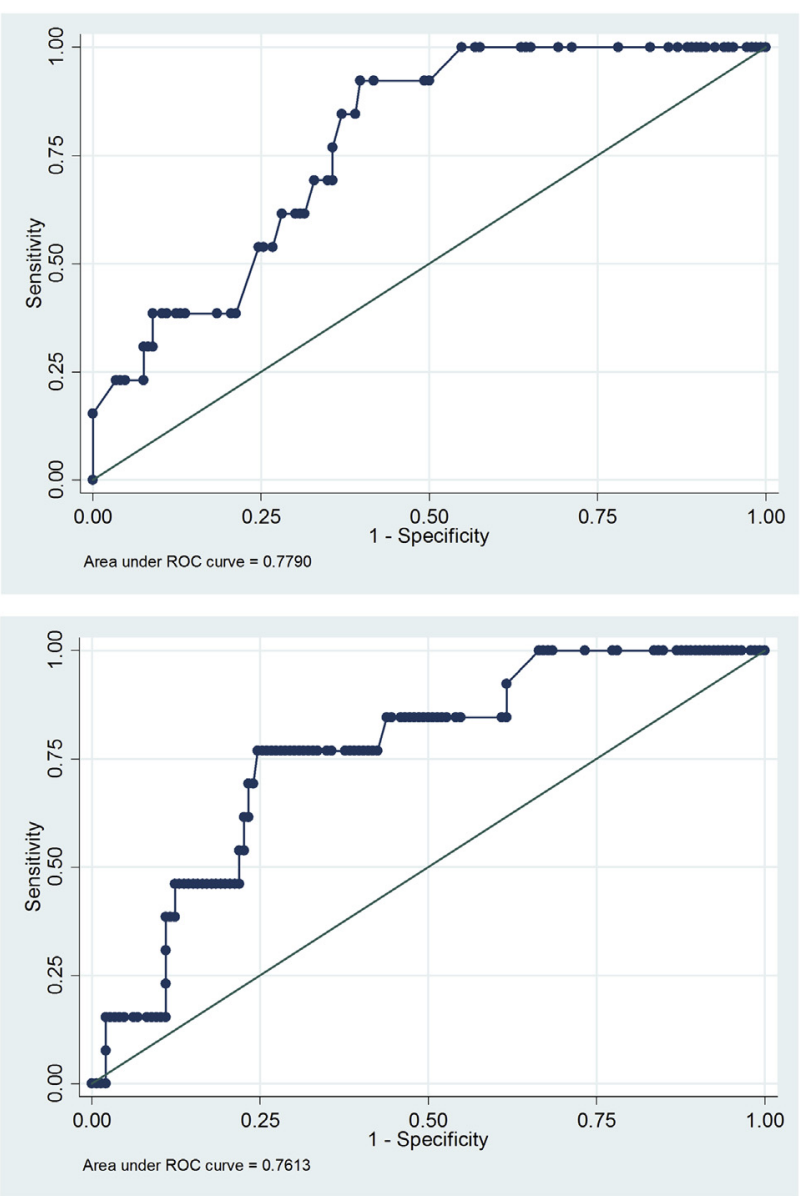

FIGURE 1. Receiver operating characteristic curves for the multivariate model including delayed sternal closure (top) and DHCA duration (bottom). ROC, Receiver operating characteristic.

with DHCA 40 minutes or more had a significantly increased seizure risk $(15 \%$ vs $5 \%$, chi-square $P=.03$; OR, 3.4; 95\% CI, 1.07-11.08; $P=.04)$. When DHCA was changed into a 10-minute scale for subjects with DHCA more than 0 minutes, for every 10-minute increase in DHCA duration time, the OR of developing seizure was 1.47 (95\% CI, 0.96-2.15).

Several alternative analyses were performed. First, an alternative regression model was explored with the cardiac defect type grouped as 1 versus 2 ventricles, and similar results were observed. Second, an alternative regression model was explored including EEG variables known in the initial hour of EEG recording, including background category, excessive interictal epileptiform discharge presence, and reactivity. The EEG background category was continuous in 30 neonates $(19 \%)$, appropriately discontinuous in 31 neonates $(19 \%)$, and excessively discontinuous in 99 neonates (62\%). EEG background category did not predict seizure occurrence on univariable analysis $(P=.85)$. Seizures occurred in 5 of 46 neonates $(11 \%)$ with excessive interictal epileptiform discharges and in 7 of 105 neonates $(6 \%)$ without excessive epileptiform discharges $(P=.06)$. Among the 112 neonates in whom reactivity could be assessed, seizures occurred in 4 of 96 neonates $(4 \%)$ with reactivity and 2 of 16 neonates $(13 \%)$ without reactivity $(P=.08)$. Multivariable analyses including these EEG variables were not substantially different than the model described previously. On multivariable analysis using delayed sternal closure, the only predictor of seizures was delayed sternal closure (OR, 4.09; 95\% CI, 1.04-15.99; $P=.04$ ). On multivariable analysis using DHCA duration, the only predictor of seizure was DHCA duration (OR, 1.04; 95\% CI, 1.00-1.08; $P=.04)$. We compared the receiver operating characteristic curve c-statistics between the model containing only clinical variables and the model containing EEG variables, and they were not significantly different.

Seizure descriptions and management are summarized in Table 2. The most commonly administered antiseizure medication was phenobarbital, followed by a combination of levetiracetam or phenobarbital. The choice of antiseizure medication and bolus parameters were left to the clinician's discretion. No patients had hemodynamic instability related to medication administration.

Nine neonates $(6 \%)$ died. Four neonates had multiorgan system dysfunction and withdrawal of technologic support on ECMO, 1 neonate had a large intracranial hemorrhage and withdrawal of technologic support on ECMO, 1 neonate had multiorgan system dysfunction and withdrawal of ventilatory and inotropic support, 1 neonate had a large intracranial hemorrhage and withdrawal of ventilatory and inotropic support, 1 neonate had a cardiac arrest and was deemed to not be an ECMO candidate, and 1 neonate had cardiac arrest and was unable to be cannulated for ECMO. Mortality was higher among neonates with than without seizures $(38 \%$ vs $3 \%, P<.01)$. Neonates with and without seizures did not have significantly different postoperative lengths of stay in the CICU (11 days for both groups, $P=.65$ ) or hospital (18 vs 17 days, $P=.85)$. When the 9 neonates who died were excluded, neonates with and without seizures still did not have significantly different lengths of stay in the CICU (11 days for both groups, $P=.69$ ) or hospital (17 vs 19 days, $P=.40)$.

\section{Brain Imaging}

Brain MRI scans were obtained in 8 of 13 neonates with seizures. Findings included diffuse periventricular leukomalacia in 5 neonates, subdural hematomas in 3 neonates, infarction in 2 neonates, microhemorrhages in 2 neonates, and intraparenchymal hemorrhage in 1 neonate. Five neonates did not undergo MRI (death in 4 and transfer to another hospital in 1) but underwent head ultrasounds that showed intraventricular hemorrhage in 2, infarction in 2, intraparenchymal hemorrhage in 2 , and subdural 
hematoma in 1. Imaging characteristics are provided in Table 2. All neonates with seizures had diffuse or multifocal imaging lesions. Four patients had seizures arising predominantly from one of their injury sites (subjects 4, 5, 10, and 12 in Table 2), but none had a single site of injury with focal seizures arising solely from that region.

\section{DISCUSSION}

This is the first report describing the impact of implementation of the ACNS guideline on routine postoperative CEEG among neonates with $\mathrm{CHD}$ after surgery with $\mathrm{CPB}$. We identified an EEG seizure incidence of $8 \%(13 / 161)$. The seizure burden was often high (status epilepticus in $62 \%$ ). Seizures were often EEG only ( $85 \%$ ), indicating that CEEG was required for identification because bedside clinical assessment for seizures without CEEG monitoring would be unreliable. The only clinical predictors of seizure occurrence available on return to the CICU postoperatively were delayed sternal closure and longer DHCA duration. Seizures also were more likely in neonates who subsequently required ECMO or experienced cardiac arrest, and seizures were associated with higher mortality.

The $8 \%$ incidence of EEG seizures in our current cohort was not significantly different from our previous report of CEEG among neonates who received care from 2001 to $2003(14 \%, 15 / 110) .{ }^{4}$ However, unlike our previous cohort in which all patients with seizures had EEG-only seizures, $15 \%$ of our current cohort of neonates had some clinical correlate to their seizures. These data are similar to the Boston Circulatory Arrest Study of children with transposition of the great arteries in which the incidences of EEG-only and electroclinical seizures were $20 \%$ and $6 \%$, respectively. ${ }^{3}$ Likewise, a study of a heterogeneous CHD cohort of neonates and infants reported perioperative (preoperative, intraoperative, and postoperative) electrographic seizures in $30 \%$ of neonates, of which $16 \%$ were electroclinical. ${ }^{19}$ In comparison, Andropoulos and associates $^{20}$ examined the occurrence of preoperative and postoperative seizures in neonates undergoing surgery with CBP and found that only 1 patient with a single ventricle had an EEG seizure, leading to an overall incidence of $1.5 \%$. The lower incidence of seizures in this last study is likely due to the routine intraoperative and postoperative administration of benzodiazepines, which were not used routinely in the other studies.

Similar to our previous report, ${ }^{4}$ electrographic seizures were most common in neonates with single-ventricle defects with arch obstruction (16\% in current report, $18 \%$ in previous report). In our prior study of clinical seizures after infant cardiac surgery, the risk of clinical seizures was also highest in those with single-ventricle defects with arch obstruction. ${ }^{2}$ This contrasts with other studies that have reported the highest seizure incidence in patients with 2-ventricle defects with aortic arch obstruction. ${ }^{19}$ In addition, we found that increasing DHCA duration predicted seizure occurrence. This finding is similar to that of the Boston Circulatory Arrest Study, in which identified risk factors for seizures included increasing duration of DHCA, the presence of a ventricular septal defect, and older age at the time of surgery. ${ }^{9}$ Likewise, we have previously reported risk factors that include coexisting genetic defects, aortic arch obstruction, ${ }^{2}$ and increasing duration of DHCA. ${ }^{2,4}$ Since our previous report, the incidence of seizures in patients who had DHCA more than 40 minutes has decreased from $24 \%$ to $15 \%$. Of note, avoidance of DHCA does not prevent seizures. In the current study, seizures occurred in 3\% of patients in whom DHCA was not used. A recent study by Gunn and associates ${ }^{19}$ described a high incidence of perioperative seizures $(30 \%)$. The operative strategy consisted primarily of antegrade cerebral perfusion at one center for all patients; in the second center, DHCA was used with only brief periods (median duration, 8 minutes [IQR 5-17]) in patients with biventricular circulation during arch reconstruction and during surgery to the atrial septum. ${ }^{19}$

In this study, on univariable analysis, seizures occurred more often in neonates who were younger at the time of surgery compared with those who were older (aged 3 vs 5 days). This variable was not a seizure predictor in our previous report ${ }^{4}$ and contradicts the previous finding of older age at the time of surgery in the Boston Circulatory Arrest Study, although it was not possible to separate age and diagnosis of ventricular septal defects as predictors for seizures. ${ }^{3}$ Seizure onset occurred at median of 20 hours after return to the CICU postoperatively. This is similar to our previous report, in which the median seizure onset time was 21 hours after surgery. ${ }^{5}$ In the Boston Circulatory Arrest Study, most seizures occurred 13 to 36 hours after surgery.

Status epilepticus was common in our cohort, occurring in $62 \%$ of neonates with seizures. This is consistent with the Boston Circulatory Arrest Study that identified a high occurrence of status epilepticus. ${ }^{3}$ Patients who had seizures were medically sicker than patients without seizures, as indicated by being more likely to return to the CICU with an open chest, to have longer DHCA durations, to experience a cardiac arrest, and to require ECMO. The occurrence of seizures in our cohort was ominous because $38 \%(5 / 13)$ of neonates with postoperative seizures died. In the Boston Circulatory Arrest Study, 2\% $(n=3)$ of infants died within 1 month of surgery, but no association with postoperative seizures was reported. ${ }^{9}$ Gunn and colleagues ${ }^{8}$ reported a $44 \%$ early mortality in neonates with hypoplastic left heart syndrome and variants who had seizures after Norwood type operations compared with $13 \%$ without postoperative seizures. 
Given increasing attention to quality assessment and cost-effective healthcare strategies, physicians must determine whether the seizure incidence and available data regarding the association between seizures and worse neurodevelopmental outcomes justify the routine use of CEEG for all neonates who undergo cardiac surgery with CBP. The ACNS guideline recommends routine monitoring for several neonatal populations who have been identified as having an especially high risk for seizures. ${ }^{15}$ Neonates at high risk of seizures include $34 \%$ to $65 \%$ of neonates treated with therapeutic hypothermia for hypoxic ischemic encephalopathy, ${ }^{21,22} 90 \%$ of neonates with stroke, ${ }^{23} 10 \%$ to $30 \%$ of neonates undergoing ECMO, ${ }^{24-26}$ and $85 \%$ of neonates with meningitis. ${ }^{27}$ The incidence of seizures in these at-risk populations is higher than has been reported in the population with $\mathrm{CHD},{ }^{3,4,9,19}$ although in many of those populations the impact of seizures on neurodevelopmental outcomes has not been studied. In adult populations, CEEG has not been shown to significantly increase hospital costs, ${ }^{28,29}$ but costeffectiveness analyses have not been performed in neonates with CHD. With implementation of the ACNS guideline at our institution, we were aiming to identify a population of neonates to target for routine postoperative CEEG monitoring. Both delayed sternal closure and longer DHCA durations predicted seizures in our multivariable model, but both ORs included a lower bounds of approximately 1 , suggesting the statistically significant findings may not be useful in focusing CEEG implementation on a high-risk group.

Over the last 3 decades, surgical and medical care improvements have increased the survival of neonates, with CHD leading to emphasis on improving functional outcome and quality of life among survivors. Outcome studies have described neurodevelopmental dysfunction in half of all survivors, characterized by mild cognitive impairment, impaired executive function, inattention and impulsive behavior, and impaired language and social skills. $^{30}$ In the Boston Circulatory Arrest Study, postoperative seizure occurrence was the medical variable most consistently related to worse neuropsychologic outcomes at 16-year follow-up, including lower scores on reading and math composites, general memory index, executive function, and visual special testing. ${ }^{13}$ In that study, only clinical seizures were treated with antiseizure medications. Most seizures were EEG-only seizures and were untreated, which may have contributed to these unfavorable outcomes. In our previous evaluation of the neurodevelopmental impact of postoperative EEG seizures that were detected and treated with antiseizure medications, seizures were associated with less severe deficits at 4 years of age, including impaired executive function and social interactions, ${ }^{31}$ compared with the Boston Circulatory Arrest Study. These studies suggest that identifying and treating seizures may reduce secondary brain injury and improve outcomes. Gunn and colleagues ${ }^{8,19}$ did not find neurodevelopmental impairment at 2-year follow-up in neonates who had perioperative seizures, but testing at this age is limited and does not test higher functions such as memory and executive function. Further, there may have been some misclassification of patients with and without seizures because the study used amplitudeintegrated EEG and not conventional full-array EEG. ${ }^{32}$ High seizure burdens have been associated with worse outcome in older critically ill children. ${ }^{33-35}$ Although the occurrence of a seizure is a marker of brain injury, there may also be secondary injury if the seizure activity is not terminated. The association between seizures and worse outcomes is consistent with animal models. In baboons with pharmacologically induced seizures and paralysis, thus producing nonconvulsive status epilepticus, severe brain injury occurred. ${ }^{36}$ Further, seizures in the immature brain have been shown to induce a cascade of events resulting in synaptic changes, altered long-term potentiation, cell injury, and cell death. ${ }^{37-39}$

Given the association between seizures and worse neurodevelopment outcomes, postoperative CEEG to identify seizures is warranted. Our investigation showed that patients who had delayed sternal closure and longer duration of DHCA had an increased risk of seizures. However, given that neonates with all categories of CHD were at risk of development of seizures and that the majority of seizures in our study were EEG only, widespread monitoring strategies are indicated in the neonatal post-CBP population. Furthermore, push-button events by bedside clinicians, including abnormal movements and hypertensive episodes concerning for possible seizures, did not have any EEG correlate indicating that bedside clinical assessment for seizures without CEEG monitoring is unreliable.

\section{Study Limitations}

First, we did not monitor patients preoperatively or intraoperatively, as has been done in previous reports. ${ }^{19,20}$ Second, we did not evaluate neurodevelopmental outcomes and thus cannot determine whether seizure occurrence was associated with adverse neurodevelopmental outcomes among survivors.

\section{CONCLUSIONS}

We implemented routine postoperative CEEG in neonates with CHD who underwent surgery with CPB in accordance with the ACNS guideline and identified an $8 \%$ incidence of postoperative EEG seizures. In the majority of neonates, the seizures were EEG only. Bedside clinical assessment for seizures without CEEG monitoring was unreliable. Neonates with all classifications of CHD had postoperative seizures. The only risk factors for 
electrographic seizures were delayed sternal closure and longer DHCA duration. Seizure occurrence was associated with more severe illness, as indicated by associations with delayed sternal closure, longer DHCA durations, postoperative cardiac arrest, and need for ECMO. Seizures were markers of brain injury, characterized by multifocal neuroimaging lesions and an association with higher mortality. Further study is needed to determine whether identification and management of seizures improve neurodevelopmental outcomes.

\section{Conflict of Interest Statement}

Authors have nothing to disclose with regard to commercial support.

You can watch a Webcast of this AATS meeting presentation by going to: http://webcast.aats.org/2014/files/ Monday/20140428_435_455pm_Maryam_Naim.mp4

The authors thank Elizabeth McBride who participated in data collection.

\section{References}

1. Abend NS, Dlugos D, Clancy RR. A review of long term EEG monitoring in critically ill children with hypoxic ischemic brain encephalopathy, congenital heart disease, ECMO, and stroke. J Clin Neurophysiol. 2013;30:134-42.

2. Clancy RR, McGaurn SA, Wernovsky G, Gaynor JW, Spray TL, Norwood WI, et al. Risk of seizures in survivors of newborn heart surgery using deep hypothermic circulatory arrest. Pediatrics. 2003;111:592-601.

3. Helmers SL, Wypij D, Constantinou JE, Newburger JW, Hickey PR, Carrazana EJ, et al. Perioperative electroencephalographic seizures in infants undergoing repair of complex congenital cardiac defects. Electroencephalogr Clin Neurophysiol. 1997;102:27-36.

4. Gaynor JW, Nicolson SC, Jarvik GP, Wernovsky G, Montenegro LM, Burnham NB, et al. Increasing duration of deep hypothermic circulatory arrest is associated with an increased incidence of postoperative electroencephalographic seizures. J Thorac Cardiovasc Surg. 2005;130:1278-86.

5. Clancy RR, Sharif U, Ichord R, Spray TL, Nicolson S, Tabbutt S, et al. Electrographic neonatal seizures after infant heart surgery. Epilepsia. 2005;46:84-90.

6. Chock VY, Reddy VM, Bernstein D, Madan A. Neurologic events in neonates treated surgically for congenital heart disease. J Perinatol. 2006;26:237-42.

7. Schmitt B, Finckh B, Christen S, Lykkesfeldt J, Schmid ER, Bauersfeld U, et al. Electroencephalographic changes after pediatric cardiac surgery with cardiopulmonary bypass: is slow wave activity unfavorable? Pediatr Res. 2005;58:771-8.

8. Gunn JK, Beca J, Penny DJ, Horton SB, d'Udekem YA, Brizard CP, et al. Amplitude-integrated electroencephalography and brain injury in infants undergoing Norwood-type operations. Ann Thorac Surg. 2012;93:170-6.

9. Newburger JW, Jonas RA, Wernovsky G, Wypij D, Hickey PR, Kuban KC, et al. A comparison of the perioperative neurologic effects of hypothermic circulatory arrest versus low-flow cardiopulmonary bypass in infant heart surgery. $N$ Engl J Med. 1993;329:1057-64.

10. Bellinger DC, Jonas RA, Rappaport LA, Wypij D, Wernovsky G, Kuban KC, et al. Developmental and neurologic status of children after heart surgery with hypothermic circulatory arrest or low-flow cardiopulmonary bypass. $N$ Engl J Med. 1995;332:549-55.

11. Rappaport LA, Wypij D, Bellinger DC, Helmers SL, Holmes GL, Barnes PD, et al. Relation of seizures after cardiac surgery in early infancy to neurodevelopmental outcome. Boston Circulatory Arrest Study Group. Circulation. 1998;97:773-9.

12. Bellinger DC, Wypij D, Kuban KC, Rappaport LA, Hickey PR, Wernovsky G, et al. Developmental and neurological status of children at 4 years of age after heart surgery with hypothermic circulatory arrest or low-flow cardiopulmonary bypass. Circulation. 1999;100:526-32.

13. Bellinger DC, Wypij D, Rivkin MJ, DeMaso DR, Robertson RL Jr, DunbarMasterson C, et al. Adolescents with d-transposition of the great arteries corrected with the arterial switch procedure: neuropsychological assessment and structural brain imaging. Circulation. 2011;124:1361-9.
14. Gaynor JW, Jarvik GP, Bernbaum J, Gerdes M, Wernovsky G, Burnham NB, et al The relationship of postoperative electrographic seizures to neurodevelopmental outcome at 1 year of age after neonatal and infant cardiac surgery. J Thorac Cardiovasc Surg. 2006;131:181-9.

15. Shellhaas RA, Chang T, Tsuchida T, Scher MS, Riviello JJ, Abend NS, et al. The American Clinical Neurophysiology Society's Guideline on continuous electroencephalography monitoring in neonates. J Clin Neurophysiol. 2011;28:611-7.

16. Clancy RR, McGaurn SA, Wernovsky G, Spray TL, Norwood WI, Jacobs ML, et al. Preoperative risk-of-death prediction model in heart surgery with deep hypothermic circulatory arrest in the neonate. J Thorac Cardiovasc Surg. 2000;119: 347-57.

17. Tsuchida TN, Wusthoff CJ, Shellhaas RA, Abend NS, Hahn CD, Sullivan JE, et al. American Clinical Neurophysiology Society Standardized EEG Terminology and Categorization for the Description of Continuous EEG Monitoring in Neonates: Report of the American Clinical Neurophysiology Society Critical Care Monitoring Committee. J Clin Neurophysiol. 2013;30:161-73.

18. Wechsler LR, Tsao JW, Levine SR, Swain-Eng RJ, Adams RJ, Demaerschalk BM, et al. Teleneurology applications: report of the Telemedicine Work Group of the American Academy of Neurology. Neurology. 2013;80:670-6.

19. Gunn JK, Beca J, Hunt RW, Olischar M, Shekerdemian LS. Perioperative amplitude-integrated EEG and neurodevelopment in infants with congenital heart disease. Intensive Care Med. 2012;38:1539-47.

20. Andropoulos DB, Mizrahi EM, Hrachovy RA, Stayer SA, Stark AR, Heinle JS et al. Electroencephalographic seizures after neonatal cardiac surgery with highflow cardiopulmonary bypass. Anesth Analg. 2010;110:1680-5.

21. Wusthoff CJ, Dlugos DJ, Gutierrez-Colina A, Wang A, Cook N, Donnelly M, et al. Electrographic seizures during therapeutic hypothermia for neonatal hypoxic-ischemic encephalopathy. J Child Neurol. 2011;26:724-8.

22. Nash KB, Bonifacio SL, Glass HC, Sullivan JE, Barkovich AJ, Ferriero DM, et al. Video-EEG monitoring in newborns with hypoxic-ischemic encephalopathy treated with hypothermia. Neurology. 2011;76:556-62.

23. Laugesaar R, Kolk A, Tomberg T, Metsvaht T, Lintrop M, Varendi H, et al Acutely and retrospectively diagnosed perinatal stroke: a population-based study. Stroke. 2007:38:2234-40.

24. Hahn JS, Vaucher Y, Bejar R, Coen RW. Electroencephalographic and neuroimaging findings in neonates undergoing extracorporeal membrane oxygenation. Neuropediatrics. 1993;24:19-24.

25. Streletz LJ, Bej MD, Graziani LJ, Desai HJ, Beacham SG, Cullen J, et al. Utility of serial EEGs in neonates during extracorporeal membrane oxygenation. Pediatr Neurol. 1992;8:190-6.

26. Piantino JA, Wainwright MS, Grimason M, Smith CM, Hussain E, Byron D, et al Nonconvulsive seizures are common in children treated with extracorporeal cardiac life support. Pediatr Crit Care Med. 2013;14:601-9.

27. ter Horst HJ, van Olffen M, Remmelts HJ, de Vries H, Bos AF. The prognostic value of amplitude integrated EEG in neonatal sepsis and/or meningitis. Acta Paediatr. 2010;99:194-200.

28. Vespa PM, Nenov V, Nuwer MR. Continuous EEG monitoring in the intensive care unit: early findings and clinical efficacy. J Clin Neurophysiol. 1999;16:1-13.

29. Ney JP, van der Goes DN, Nuwer MR, Nelson L, Eccher MA. Continuous and routine EEG in intensive care: utilization and outcomes, United States 2005-2009. Neurology. 2013;81:2002-8.

30. Shillingford AJ, Glanzman MM, Ittenbach RF, Clancy RR, Gaynor JW Wernovsky G. Inattention, hyperactivity, and school performance in a population of school-age children with complex congenital heart disease. Pediatrics. 2008 121:e759-67.

31. Gaynor JW, Jarvik GP, Gerdes M, Kim DS, Rajagopalan R, Bernbaum J, et al Postoperative electroencephalographic seizures are associated with deficits in ex ecutive function and social behaviors at 4 years of age following cardiac surgery in infancy. J Thorac Cardiovasc Surg. 2013;146:132-7.

32. Shellhaas RA, Soaita AI, Clancy RR. Sensitivity of amplitude-integrated electroencephalography for neonatal seizure detection. Pediatrics. 2007;120:770-7.

33. Topjian AA, Gutierrez-Colina AM, Sanchez SM, Berg RA, Friess SH, Dlugos DJ, et al. Electrographic status epilepticus is associated with mortality and worse short-term outcome in critically ill children. Crit Care Med. 2013;31:215-23.

34. Wagenman KL, Blake TP, Sanchez SM, Schultheis MT, Radcliffe J, Berg RA, et al. Electrographic status epilepticus and long-term outcome in critically ill children. Neurology. 2014;82:396-404.

35. Payne ET, Zhao XY, Frndova H, McBain K, Sharma R, Hutchison JS, et al Seizure burden is independently associated with short term outcome in critically ill children. Brain. 2014:137:1429-38. 
36. Meldrum BS, Vigouroux RA, Brierley JB. Systemic factors and epileptic brain damage. Prolonged seizures in paralyzed, artificially ventilated baboons. Arch Neurol. 1973;29:82-7.

37. Ben-Ari Y, Holmes GL. Effects of seizures on developmental processes in the immature brain. Lancet Neurol. 2006;5:1055-63.

38. Holmes GL, Gairsa JL, Chevassus-Au-Louis N, Ben-Ari Y. Consequences of neonatal seizures in the rat: morphological and behavioral effects. Ann Neurol. 1998:44:845-57.

39. Zhou C, Lippman JJ, Sun H, Jensen FE. Hypoxia-induced neonatal seizures diminish silent synapses and long-term potentiation in hippocampal CA1 neurons. J Neurosci. 2011;31:18211-22.

Key Words: Electroencephalography, EEG, neonatal seizures, congenital heart disease, cardiopulmonary bypass

\section{Discussion}

Dr F. Pigula (Boston, Mass). The article by Naim and colleagues spotlights an important issue in neonatal congenital heart surgery. As a specialty, I think we've tended to underappreciate the significance of perioperative seizures.

There is good evidence from the Boston Circulatory Arrest Study that was initiated in the early 1990s that perioperative seizures portend downstream difficulties in patients.

There have been multiple longitudinal evaluations of these patients. In the first longitudinal analysis, perioperative seizures were still associated with neurologic abnormalities in the 1-yearold patients, specifically in the psychomotor developmental domain, and there was a greater incidence of brain abnormalities by MRI in these patients. When they looked at the same patients 16 years later, perioperative seizures still predicted worse outcomes in multiple areas, including measurements in reading and math skills, executive functioning, and general memory skills, among others.

In the experience presented today, seizures occurred in $8 \%$ of the patients, but, and this is an important point, $85 \%$ of those patients experiencing seizures were only by EEG documentation; in other words, they would have gone undetected without EEG monitoring. Several of these patients were in status epilepticus.

I think, although it didn't come out in your presentation, I took from your article that all patients experiencing a seizure had documented brain abnormalities by imaging, either MRI or ultrasound. Is that correct?

Dr Naim. Yes, that is correct.

Dr Pigula. Now, although most of the groups that have examined this problem, and you're not the first group to have published on this, there has been a reported incidence of $5 \%$ to $26 \%$ of perioperative seizures in patients. In almost all of these studies, every patient who has had a seizure has had documented brain abnormality by imaging techniques whenever they've looked. So the way I've interpreted these data is that a seizure is a sign of an underlying brain injury, much like a fever is a sign of an underlying infection. You've made a good case for the routine postoperative surveillance procedures, and I'm sure everyone would agree that treatment of a seizure is a good thing once you document it.

Is there any evidence or information suggesting or showing us that the early identification and prompt treatment of a seizure improve outcomes in developmental domains or mortality?
Dr Naim. To address your first question, I think the data actually come from your institution. In the Boston Circulatory Arrest Study, the incidence of seizures was $20 \%$, and the majority of these were EEG seizures that were not treated. Only $6 \%$ of patients actually had clinical seizures, and these patients were treated with anticonvulsant medications.

If you look at the 16-year neurodevelopmental outcomes of this cohort of patients, we find that the most important predictor of a poor neurodevelopmental outcome was actually the occurrence of seizure after the neonatal operation. These data are compelling. Dr Gaynor recently published his results of the apolipoprotein E genotype cohort, and when we look at these neonates, those who had seizures at the Children's Hospital of Philadelphia were actually treated with antiseizure medication even if they had EEG-only seizures, and all these neonates were treated whether they had subclinical seizures or EEG seizures. At the 4-year point, we have seen less severe deficits compared with what was reported by the Boston Circulatory Arrest Study at 16 years.

Dr Pigula. One of the important differences is the real-time evaluation and interpretation of the EEG in your study, whereas in other studies that's not necessarily the case. So the opportunity to treat is not necessarily present in the other studies, although it is in your study.

How do you recommend we integrate this information into the management of neonates, especially when one quarter to one third of them will present to the surgeon with an underlying brain abnormality by imaging if we really look for it?

Dr Naim. There are emerging data that seizures themselves cause secondary brain injury. I think the way to move forward, because our emphasis has really changed now to improving neurodevelopmental outcomes of our patients, is to monitor them postoperatively. We are seeing better neurodevelopmental outcomes, or there is a suggestion that if we treat seizures, we also are finding out that children who have prolonged seizures, or seizures themselves, can cause secondary brain injury. At our institution, we are continuing routine postoperative monitoring, and it has been recommended by the ACNS.

Dr Pigula. It is recommended by them. They also qualify their recommendations a bit on the basis of available resources. So it's a bit of a soft recommendation, at least my interpretation of that article.

Dr C. Backer (Chicago, Ill). Before we take the questions, let's just survey the audience. How many surgeons are routinely monitoring their neonates for seizures after neonatal open surgery?

(Show of hands.)

I only see 8, maybe 9 hands.

How many people are not routinely monitoring for seizures?

(Show of hands.)

It looks like at least $80 \%$ to $90 \%$ of the audience. It appears that we are not following the recommendations of the ACNS.

Dr C. Fraser (Houston, Tex). I have a long way to get to a short question. Great discussion and nicely presented article, very helpful. As you probably know, we in Texas have had a different approach to perioperative neurosurveillance and oxygen delivery during the operation. We conducted a prospective EEG evaluation of our patients, we didn't act on them clinically, but reported a lower incidence of seizures than what you've reported here. Now, admittedly, these were very selected patients; they were 
mature babies, nonsyndromic, and weren't treated with ECMO. These are clearly a much sicker population.

But one point at this meeting, I think 2 years ago, that Dr Gaynor made, which is correct, is that we have a more liberal use of benzodiazepines in the operating room, and so is that a different practice that you have at the Children's Hospital of Philadelphia.

Dr Naim. Yes, it is. We do not routinely use benzodiazepines. In reviewing the literature, the other group that have published on this was the group from Australia, and they reported a high incidence of perioperative seizures $(\sim 30 \%)$, and they also do not use routine benzodiazepine in the operating room.

Dr Fraser Well, should you?

Dr Naim. There is extensive literature, especially in the premature population, about the effects of benzodiazepine use and neurodevelopmental outcome. We're all interested in seeing what all these medications, including anesthetics, benzodiazepines, and narcotics, do to our patients in terms of long-term neurodevelopmental outcomes. Your point is excellent, and it's something to think about, but there are other effects that all these medications have on our patients and they need to be studied.

Dr J. Tweddell (Milwaukee, Wis). That was an excellent study and presentation. Do you have any idea how much this costs?

Dr Naim. No, I don't. I knew that this question was going to come up, and I actually asked our neurophysiologist who worked with me, and he didn't know how much it costs.

Dr Tweddell. So a technician has to be observing the EEG continually to act on it, correct?

Dr Naim. Yes. At the Children's Hospital of Philadelphia, we have an in-house technician who is available 24 hours a day 7 days a week.

Dr Tweddell. Although the data you suggested, the Boston Circulatory Arrest Study without treatment for EEG seizures, versus Dr Gaynor's study showing neurodevelopmental outcomes for patients whose EEG seizures were treated, those aren't really contemporary groups, and I'm sure they differ in many other ways. Are there any more high-level data to suggest that treating neonatal seizures improves neurodevelopmental outcome?

Dr Naim. Not that I know of.

Dr Tweddell. So recommending continuous EEG monitoring, are we there yet?

Dr Naim. I think your point is excellent. In terms of just going back to the cost part of it, the cost analysis has been done in adults with continuous EEG monitoring. In adult patients in the intensive care unit, there are 2 studies showing that there is no increase in hospital costs for EEG monitoring.

To your second point is, as I said before, our emphasis is to improve neurologic outcomes in our patients. Although seizures are probably just a biomarker of underlying brain injury, they also can independently cause secondary brain injury, and that's something we can detect and potentially treat. It will be interesting to see Dr Gaynor's 16-year outcomes and compare those head-to-head with the Boston Circulatory Arrest Study. For the time being, this is something that we can potentially intervene on and treat, so I think we're going to continue to do it at this time.
Dr J. Hirsch-Romano (Ann Arbor, Mich). Just to clarify, the ACNS recommendations currently for EEG monitoring are based on expert opinion?

Dr Naim. I think the recommendations are based on just the small number of studies showing an increased incidence of subclinical seizures after cardiac surgery.

Dr S. Gandhi (Vancouver, BC, Canada). I have 3 short method questions. First, is this EEG monitoring or video EEG monitoring?

Second, regarding the EEG technician reading the studies for the first 48 hours, is the technician positioned at the bedside or is this remote monitoring as part of their EEG reading responsibility for the entire hospital? Certainly, where I live, getting funding for somebody to read an EEG for 48 hours is near impossible, or impossible.

What do you think about the Brainz monitor (Natus Instruments, San Carlos, Calif), which is sort of a 3-lead EEG that many neonatal intensive care units use to monitor seizures in children that can be read by a bedside nurse?

Dr Naim. To answer your first question, this was video EEG monitoring.

To answer your second question, this is an EEG technician who is present for the entire hospital and reviews EEGs continuously. If there is something suspicious for seizures, the EEG technician contacts the neurophysiologist on call, who also reviews the EEG to see definitively whether it's a seizure or not.

Regarding your third question, is this amplitude-integrated EEG that you're talking about?

Dr Gandhi. Yes.

Dr Naim. I think we have shown from our institution that sometimes it's not entirely accurate in detecting seizures. Dr Gaynor can correct me if I'm mistaken.

Dr C. Backer (Chicago, Ill). Bill, come on up to the microphone. While he's coming up, I just want to ask the audience, how many people are routinely using benzodiazepines in their standard postoperative management of neonates?

(Show of hands.)

How many people are not using benzodiazepines?

(Show of hands.)

It looks like approximately $40 \%$ are and $60 \%$ are not, because that would mask the seizures.

Dr Naim. Yes. Or suppress the seizures.

Dr J. W. Gaynor (Philadelphia, Pa). I agree that benzodiazepines might be a strategy, but there is increasing evidence that all the benzodiazepines, the volatiles, the narcotics, all may affect neurodevelopment as well. I think it is a potential therapeutic intervention and might be more cost-effective as a source for future study.

In our original cohort of 170 kids who had the 10-lead EEG, we also generated the 3-lead amplitude EEG and had a blinded reader read them, and the detection of seizures was less accurate with the amplitude EEG, so that's why we continue with the full EEG.

Dr R. Neirotti (Cambridge, Mass). Did you find any difference between those patients undergoing operation with deep hypothermia with circulatory arrest and those with $\mathrm{CPB}$ alone? 
Dr Naim. I think we found that in both sets of patients. Are you asking about whether there was a difference between those who had DHCA versus those who didn't?

Dr Neirotti. Yes.

Dr Naim. We found that there was a high incidence in those with DHCA and that increasing durations of DHCA were associated with seizures.

Dr Neirotti. Do you have any information about the rate of cooling and the duration of the cooling time in your deep hypothermia and circulatory arrest group?

Dr Naim. We cool to a temperature of $18^{\circ} \mathrm{C}$ and it's over 15 to 20 minutes.

Dr J. Hirsch-Romano (Ann Arbor, Mich). It's interesting if you extrapolate from all of your data for neurodevelopmental outcomes not showing an association with circulatory arrest or duration of circulatory arrest that despite having increased seizure burden, those patients are not experiencing a late increased impairment in neurodevelopmental outcomes.

Dr Gaynor. When we looked at the multivariable analysis, use of circulatory arrest was not an independent risk factor. There are multiple things that are collinear that went along, and it was an independent risk but not a risk factor.

Dr Hirsch-Romano. Thank you for the clarification.

Dr H. Walters (Detroit, Mich). Our cardiac intensivists tell us that the routine use of benzodiazepines may impair neurodevelopmental function. If we believe those data, I would be reluctant to use them routinely.

Dr Backer. Maybe someone should present something on this next year.

Readers who found these articles interesting may also like to read the following papers found in recent and future issues of our sister publications, Seminars in Thoracic and Cardiovascular Surgery and Operative Techniques in Thoracic and Cardiovascular Surgery!

\section{Congenital Heart Disease}

Current Readings: Jeffrey Jacobs. Long Term Management of Patients Undergoing Successful Pediatric Cardiac Surgery. Semin Thorac Cardiovasc Surg. Summer 2014;26(2):132-144.

Current Readings: Brian Kogon. Pulmonary Valve Replacement for Pulmonary Valve Insufficiency in Formerly Repaired Tetralogy of Fallot Patients. Semin Thorac Cardiovasc Surg. Expected publication August 2015.

Original Submission: Meena Nathan. Technical Performance Score as a predictor for post discharge reintervention in valve sparing Tetralogy of Fallot repair. Semin Thorac Cardiovasc Surg. 2014;26(4):297-303.

Editorial Commentary: Jonathan Chen. Technical performance anxiety: utility of the Technical Performance Scale in predicting later intervention after repair of Tetralogy of Fallot. Semin Thorac Cardiovasc Surg. 2014;26(4):304-305.

Shi-Joon Yoo. MRI as a decision making tool in congenital heart disease surgery. Oper Tech Thorac Cardiovasc Surg. Summer 2014;19(2):152-163.

Pascal Vouhe. Valve Sparing Konno and HOCM in Children. Oper Tech Thorac Cardiovasc Surg. Summer 2014;19(2):164-178.

Jose Pedro da Silva. Pulmonary root translocation for anatomical repair of congenitally corrected transposition of the Great Arteries Oper Tech Thorac Cardiovasc Surg. 2014;19(3):304-323. 